\title{
Use of cone-beam computed tomography during management of a double-rooted maxillary lateral incisor: a 6-month follow-up case report
}

\author{
Selin Göker Kamalı, Şeyma Şentürk, Dilek Türkaydın, Yıldız Garip Berker \\ Department of Endodontics, Marmara University Faculty of Dentistry, Istanbul, Turkey
}

Internal anatomic variations in root canal systems affect the success of endodontic therapy. Missed canals and complex anatomic variations may cause endodontic failure. Maxillary lateral incisors frequently have a single root with a single radicular canal system. This case report describes the endodontic treatment of a two-rooted maxillary lateral incisor which was diagnosed using conventional radiography and cone beam computed tomography.

Keywords: Cone-beam computed tomography; double-rooted; maxillary lateral incisor; three-dimensional.

Cuccessful non-surgical endodontic management de$\checkmark$ pends on the elimination of infection and prevention of re-infection of the root canal system. However, missed canals and complex anatomic variations may cause endodontic failure. Therefore, it is essential to understand the morphology of root canals. Several dental anatomic studies describe maxillary lateral incisors as teeth with a single root and single canal. ${ }^{[1-4]}$ But two-rooted maxillary lateral incisors have been demonstrated in numerous case reports. ${ }^{[5,6]}$

The aim of this case report was to present the root canal treatment of a maxillary lateral incisor with an anatomic variation which was diagnosed using conventional radiography and cone beam computed tomography.

\section{Case report}

A 45-year-old female patient was referred to the Department of Endodontics, Marmara University, Istanbul, by her general dental practitioner for root canal retreatment of her upper right lateral incisor.

Enquiry into the patient's medical history revealed that she was healthy and currently not using any medication. The patient reported a possible traumatic history a year ago.

No coronal morphological variation, caries, restoration, or discoloration was noted on initial clinical examination. The tooth was not sensitive to percussion. There was no evidence of swelling or sinus tract. Gingival probing depth and tooth mobility were within physiologic limits. The tooth did not respond to electric and thermal pulp sensibility tests. The tooth was diagnosed with asymptomatic apical periodontitis after radiographic evaluation which revealed that the maxillary right lateral incisor had two distinctive roots and radiolucency in the periapical region (Fig. la). CBCT examination confirmed that both

Correspondence: Dr. Selin Göker Kamalı. Başıbüyük Mahallesi, Başıbüyük Yolu 9/3,

34854 Başıbüyük, 34854 Maltepe, İstanbul, Turkey.

Tel: +90 216-6276272 e-mail: dtselingoker@gmail.com

Submitted: July 04, 2017 Accepted: September 17, 2017 
upper right and left lateral incisors had a second root canal showing a Vertucci class IV configuration (Fig. 2a, b).

After administration of local anesthetic and isolation using a rubber dam, an endodontic access cavity was prepared, and two separate canal orifices were found in the buccopalatal directions. Working lengths were determined using an electronic apex locator, and periapical radiograph with \#10 K files was taken (Fig. lb). The root canals were prepared using MTwo NiTi files up to size 25/.06 under copious irrigation with $5.25 \% \mathrm{NaOCl}$. The root canals were dried with sterile paper points, and an interappointment dressing of calcium hydroxide paste (Calcicur; VOCO, Cuxhaven, Germany) was applied and the access cavity was restored with temporary restorative material (3 M ESPE AG, Seefeeld, Germany). One week later, the tooth was asymptomatic. After isolation with a rubber dam, the restorative material and cotton pellet were removed. \#25 K file and $5.25 \% \mathrm{NaOCl}$ irrigation were used to remove the calcium hydroxide paste. The root canals were irrigated with $5.25 \% \mathrm{NaOCl}, 17 \%$ EDTA, and again $\mathrm{NaOCl}$ for the final irrigation and dried using sterile paper points. Root canals were obturated with gutta-percha and a resin based sealer (AH Plus, Dentsply, York, PA) (Fig. lc, 2c).

Six-month Follow-up: The tooth was clinically asymp- tomatic. Periapical radiograph and CBCT imaging showed completely a healed lesion (Fig. 1d, 2d).

\section{Discussion}

Knowledge on the morphology of a root canal system is required for successful endodontic treatment. The incidence of two canals in maxillary lateral incisors is extremely rare. Vertucci has reported that maxillary incisors present a single root and single canal. However, numerous case reports have shown two, ${ }^{[7,8]}$ three ${ }^{[5]}$ and even four ${ }^{[9,10]}$ canals. Clinically, maxillary lateral incisors with anatomic variations often indicate a fusion, ${ }^{[11]}$ gemination, ${ }^{[12]}$ dens invaginatus, ${ }^{[10]}$ or a palatogingival groove. There was no fusion or gemination in the present case. The tooth did not have a single larger crown, two crowns, or roots fused together ${ }^{[13]}$ Moreover, there was no evidence in relation to enamel or dentin invagination in the preoperative radiograph; therefore, dens invaginatus was not considered. Root duplication may occur following intrusive luxation of primary teeth. ${ }^{[14]}$ However, traumatic injury of primary teeth was not an etiologic factor in the present case because two-rooted maxillary lateral incisors were found bilaterally.

The guidelines of the American Association of Endodontists, the American Academy of Oral and Maxillofacial

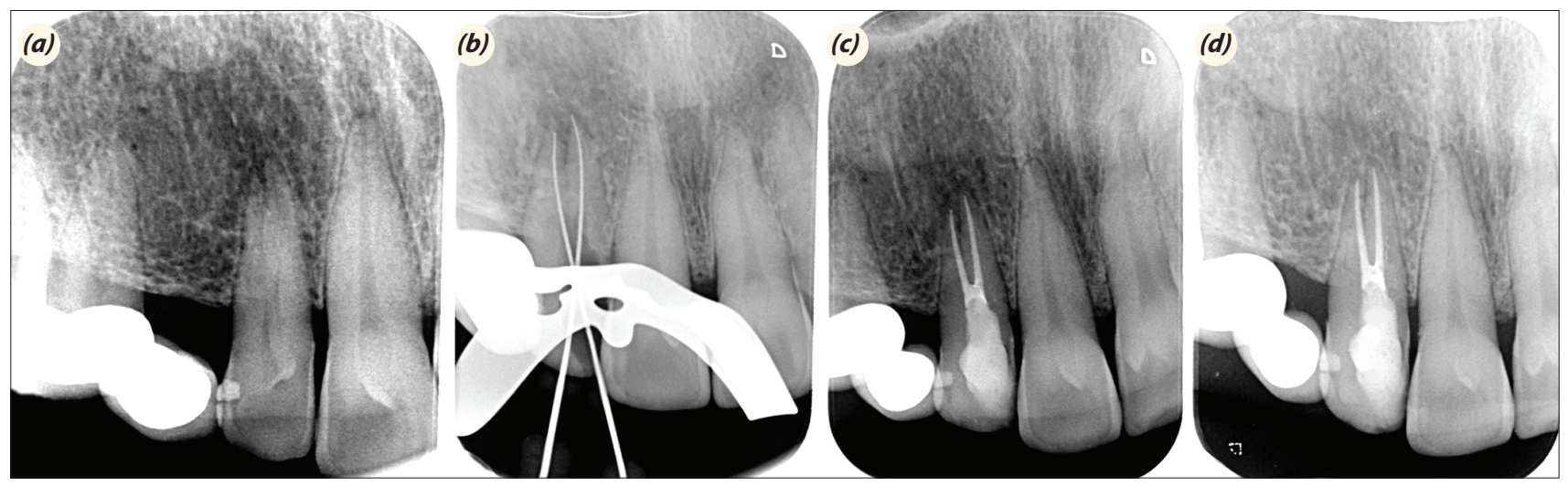

Fig. 1. (a) Preoperative periapical radiograph, (b) working length of the periapical radiograph, (c) postoperative periapical radiograph, and (d) periapical radiograph at the 6-month follow-up.
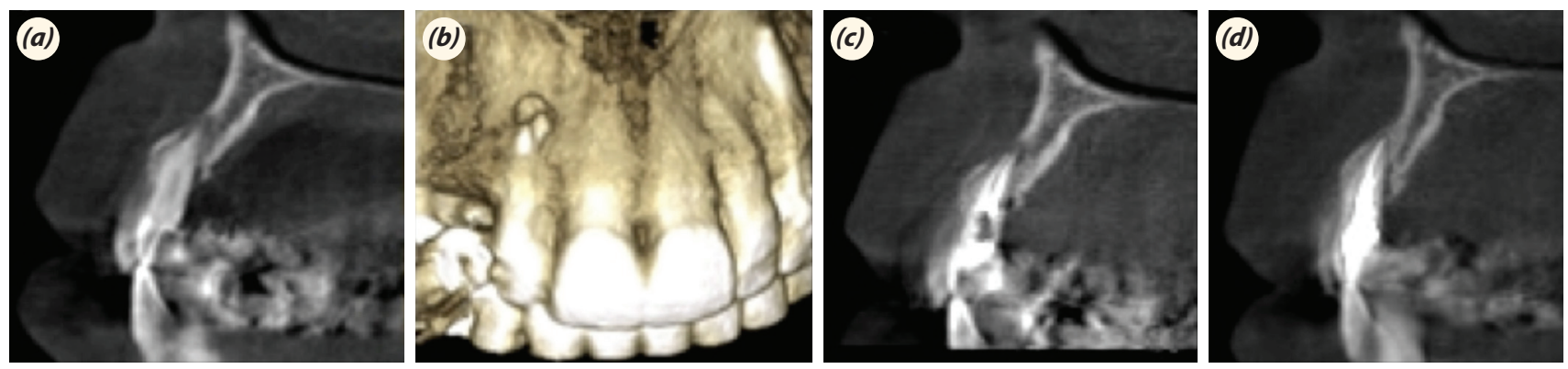

Fig. 2. (a) Preoperative $C B C T$ image, (b) preoperative $3 \mathrm{D}$ image, (c) postoperative $C B C T$ image, and (d) $C B C T$ image at the 6-month follow-up. 
Radiology, and the European Society of Endodontology recommended the use of CBCT in various situations, including abnormal anatomy. ${ }^{[15,16]}$ Therefore, cone beam computed tomography was used as a diagnostic tool by many authors for evaluating extra canals or roots. ${ }^{[9]}$ In this case, CBCT scanning was used for three-dimensional analysis of the root canal system with detection of the location of roots. Buccal and palatinal canals were not clearly detectable on conventional radiographs because of superimposition. Moreover, during preparation of the endodontic access cavity, it was difficult to find the canal orifices because of Vertucci Type IV root canal system. Therefore, CBCT images were analyzed to avoid over-extension, gouging, and even perforation in our endodontic access cavity. As a consequence, CBCT was used for a thorough understanding of the root canal morphology.

Studies have shown that one-visit root canal treatment can create favorable environmental conditions for periapical repair similar to the two-visit therapy when calcium hydroxide was used as antimicrobial dressing. ${ }^{[17]}$ However, in this case, prolongation of treatment duration because of a complex root canal system and trauma history led to the implementation of an interappointment dressing of calcium hydroxide.

In this case, the cold lateral condensation (CLC) technique was used. CLC is a very popular obturation technique; however, injectable gutta-percha and continuous wave of condensation fill the canal irregularities better than cold lateral condensation. ${ }^{[18]}$ On the other hand, thermoplastic filling techniques like thermafill could not be used in the present case because if one of the root canals was filled with thermafill, the other canal orifice was closed with gutta-percha and the canal could not be filled.

\section{Conclusion}

Internal anatomic variations of the root canal system have a role in the success of endodontic therapy. Thereby, the clinician should be careful during radiographic evaluation and if necessary, should use three-dimensional imaging techniques.

Conflict of interest: None declared.

\section{References}

1. Vertucci FJ. Root canal anatomy of the human permanent teeth. Oral Surg Oral Med Oral Pathol 1984;58:589-99.

2. Calişkan MK, Pehlivan Y, Sepetçioğlu F, Türkün M, Tuncer SS. Root canal morphology of human permanent teeth in a Turkish population. J Endod 1995;21:200-4. [CrossRef]

3. Sert $S$, Bayirli GS. Evaluation of the root canal configura- tions of the mandibular and maxillary permanent teeth by gender in the Turkish population. J Endod 2004;30:3918. [CrossRef]

4. Pineda F, Kuttler Y. Mesiodistal and buccolingual roentgenographic investigation of 7,275 root canals. Oral Surg Oral Med Oral Pathol 1972;33:101-10, [CrossRef]

5. Walvekar SV, Behbehani JM. Three root canals and dens formation in a maxillary lateral incisor: a case report. J Endod 1997;23:185-6. [CrossRef]

6. Pereira AJ, Fidel RA, Fidel SR. Maxillary lateral incisor with two root canals: fusion, gemination or dens invaginatus? Braz Dent J 2000;11:141-6.

7. Rao Genovese F, Marsico EM. Maxillary central incisor with two roots: a case report. J Endod 2003;29:220-1.

8. Levin A, Shemesh A, Katzenell V, Gottlieb A, Ben Itzhak J, Solomonov M. Use of Cone-beam Computed Tomography during Retreatment of a 2-rooted Maxillary Central Incisor: Case Report of a Complex Diagnosis and Treatment. J Endod 2015;41:2064-7. [CrossRef]

9. Kottoor J, Murugesan R, Albuquerque DV. A maxillary lateral incisor with four root canals. Int Endod J 2012;45:393-7. [CrossRef]

10. Nosrat A, Schneider SC. Endodontic Management of a Maxillary Lateral Incisor with 4 Root Canals and a Dens Invaginatus Tract.J Endod 2015;41:1167-71. [CrossRef]

11. Cunha RS, Junaid A, Mello I. Unilateral fusion of a supernumerary tooth to a maxillary permanent lateral incisor: a report of a rare case. J Endod 2015;41:420-3. [CrossRef]

12. Wong M. Treatment considerations in a geminated maxillary lateral incisor. J Endod 1991;17:179-81. [CrossRef]

13. Hatton JF, Ferrillo PJ Jr. Successful treatment of a twocanaled maxillary lateral incisor. J Endod 1989;15:216-8.

14. Maghsoudlou A, Jafarzadeh H, Forghani M. Endodontic treatment of a maxillary central incisor with two roots. J Contemp Dent Pract 2013;14:345-7. [CrossRef]

15. American Association of Endodontists; American Academy of Oral and Maxillofacial Radiology. Use of conebeam computed tomography in endodontics Joint Position Statement of the American Association of Endodontists and the American Academy of Oral and Maxillofacial Radiology. Oral Surg Oral Med Oral Pathol Oral Radiol Endod 2011;111:234-7. [CrossRef]

16. European Society of Endodontology, Patel S, Durack C, Abella F, Roig M, Shemesh H, Lambrechts P, et al. European Society of Endodontology position statement: the use of CBCT in endodontics. Int Endod J 2014;47:502-4.

17. Figini L, Lodi G, Gorni F, Gagliani M. Single versus multiple visits for endodontic treatment of permanent teeth: a Cochrane systematic review. J Endod 2008;34:1041-7.

18. Collins J, Walker MP, Kulild J, Lee C. A comparison of three gutta-percha obturation techniques to replicate canal irregularities. J Endod 2006;32:762-5. [CrossRef] 